DOI: 10.20287/ec.n25.v2.a10

\title{
Communication and Humanities: a post-conventional approach
}

\author{
João Carlos Correia \\ University of Beira Interior \\ joao.correiallabcom.ubi.pt
}

\begin{abstract}
What do humanities bring to the study of communication? What concept of humanities can help us understand communication? Do communication studies belong to the humanities or to the social sciences field? In spite of a recent turn in communication research towards empirical data that seems to be supported by a generation of young researchers, communication sciences have almost always maintained, in their many branches, the existence of critical approaches highlighting a powerful link to the role of language and symbols and their many connections to social structures, placing particular emphasis on the phenomena of meaning and relation. Human life is essentially a life of meaning, of reflexive thought and communication. My hypothesis involves considering this concern with relation as a social phenomenon as what distinguishes it epistemically. I also believe that this distinction involves extensive attention on the nature of the human, helping maintain a productive bridge with humanities and culture.
\end{abstract}

Abstract

Issues such as the role of symbols in social life are related to the constitution of subjectivity and the transmission of cultural heritage in life-world, bringing questions concerning truth, rationality, the conditions necessary for autonomy of the self and the nature of human agency to an on-going theoretical debate.

Following this tradition, attempts are made to establish communication as a discipline which finds its foundations in the concept of mediated interaction and as the discipline that expresses the relational nature of human agency. Following this perspective, the field of communication studies, in a somewhat similar way to cultural studies, has redefined itself by dealing with new cultural approaches, with the help of American cultural studies (particularly James Carey), critical theory, hermeneutics, symbolic interactionism, and critical realism as theoretical keys to unveiling the dialogue between humanities and social sciences that crosses through the communications field.

$\mathrm{T}$ HE communication studies field is a privileged one for understanding some controversial approaches to the delimitation of social sciences and humanities. The polysemy of the concept sometimes raises difficulties in understanding what "communication" means when we use it.

A Revista Estudos em Comunicação é financiada por Fundos FEDER através do Programa Operacional Factores de Competitividade - COMPETE e por Fundos Nacionais através da FCT - Fundação para a Ciência e a Tecnologia no âmbito do projeto Comunicação, Filosofia e Humanidades (LabCom.IFP) UID/CCI/00661/2013.
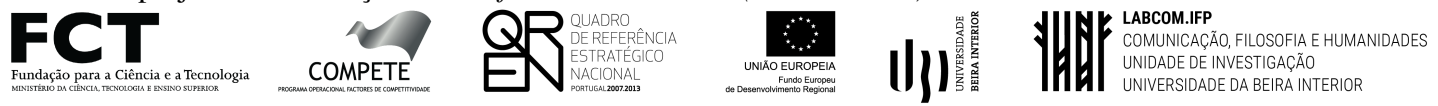

Estudos em Comunicação no 25, vol. 2, 143-152

Dezembro de 2017 
Communication departments and research centres are diversified, heterogeneous spaces where one can observe multiple sets of objects and world-views, theoretical frameworks and methodologies.

For instance, in the United States, the National Communication Association (NCA) is defined as the association that "advances communication as the discipline that studies all forms, modes, media and consequences of communication through humanistic, social scientific and aesthetic inquiry. Indeed, in many ways, NCA and its members constantly negotiate the duality of communication as both a social science and a humanities discipline" (Parry-Giles, 2013).

One theoretical categorisation, influenced by naturalist epistemology, turns the communication process into a linear one, adjusted to a unilateral vision of manipulation by hegemonic holders of power. Communication is seen as exerting the unilateral imposition of messages that aim to consolidate the power of ruling classes. This approach makes the reception process a one-dimensional determination of meaning by agents endowed with symbolic power. The elite theories of power and democracy insist on dismissing legitimacy and recognition as crucial concepts in the interpretative and hermeneutic process.

Bringing the problem to the current days, the neoliberal logic of governmentality seems to avoid any reference to recognition or legitimacy, closing the path to normative claims. Indeed, neoliberal discursive practices bring a conception of communication in which the ethical and political dimension of the struggle for recognition is largely banned, with severe impacts on collective life. The neoliberal logic applied to communicative processes minimises inquiries on the legitimacy or illegitimacy of their processes, preferring to ask for efficiency and skills that are suitable to obtaining certain effects: success or failure replacing the question of the legitimacy and meaning of the practices used (Foucault, 6; 14; 21; 23; 40; 44).

It is justifiable to call attention to the resemblance between logical positivism and the way elite theories and neoliberal approaches seek expression in terms of a particular focus on contradiction and inconsistency (Foucault, 2008: 33). The multiplicity of voices, particularly their diversity and the reciprocity of contradictory claims, is seen as an entropic element that disturbs the efficient transmission of data. The epistemological grounds of communication sciences are far from being indifferent, bearing in mind an extensive discussion on the very nature of communication and its democratic role. The positivist advocacy for the extension of methods from natural sciences to the study of human social life is linked to strategies of power, dismissing forms of critical understanding. In fact, some variants of positivism rephrase metaphysics in a scientific language: they are not just concerned with giving accounts of the nature of the world, but they also derive authoritative norms for human conduct. They provide rules of conduct to follow for accepting some kinds of institutional arrangements rather than others (Benton and Craib, 2001: 46). They become unable to understand the plurality of forms of reasoning that cross the communicative process.

In their everyday discourses, the elite and functionalist theories are strangely similar to other ideologies that claim the status of science, considering the economic factor as the dominant one for explaining politics. In all these approaches, there are considerable shadows obscuring the complex dimensions of the communicative process, reducing it to a narrow sender-receiver paradigm of data transmission. Even more strangely, those successful theoretical efforts from elite theory emerge at 
a time in the zeitgeist when the strong idea of the network seems to be key to understanding social reality.

In my view, the only perspective that brings autonomy to the communication field, allowing it to embrace all the dimensions of the communicative process, is one that acknowledges intersubjective experience and mediated interaction as the proper objects of the communication studies field.

As John Carey says: "Whatever the details of the production and reproduction of social life, it is through communication, through the intergraded relations of symbols and social structure, that societies, or at least those with which we are most familiar, are created, maintained, and transformed" (Carey, 1989: 109-10). So, "Communication, through language and other symbolic forms, comprises the ambiance of human existence" (Carey, 1989: 24).

While the domination model of social experience oversimplifies cultural transactions, which always contain elements of collaboration, dialogue, ritualised sharing or interaction, a "progress" model alongside it that lies in a fetishist approach to technology may be similarly reductive, masking a rationale for established ways of thinking and underestimating the individual and interactive dimensions of culture.

In order to circumscribe the domain of communication studies, one must consider the communicative process not as the transmission of symbols but as a human activity that aims to build and change its environment in order to give it a human meaning.

Communication may be understood as the essence of social relations and society, which are not just something held together by the "glue" of communication but build up communication themselves. Society is a network of symbolic connections. This very concept of a human being acting in the world, not as a solipsistic agent, is the one that suits a communicative approach to the phenomenon of society (and not vice-versa). At the same time, it demands a style of reflection that involves a dialogue with humanities, insisting on the primacy of relation. It was not by mere chance that Mrs. Thatcher firmly stated her strong sociological convictions: "There is no such thing as society. There are individual men and women, and there are families" (Woman's Own, 3 October 1987 cit. in Clark, 2005: 51).

In this perspective, the communicative approach will lose its density, narrowing communication to the process of data transmission among isolated individuals.

This resilience of the metaphysical approach to society is described by Norbert Elias: "understood either as a mere accumulation, an additive and unstructured collection of many individual people or as an object existing beyond individuals and incapable of further explanation. In this latter case the words available to us, the concepts which decisively influence the thought and action of people growing up within their sphere, make it appear as if the single human being, labeled the individual, and the plurality of people conceived as the society were two ontologically different entities" (Elias, 2001: vii).

Against this ontological difference, Elias claims:

"each individual person is really tied; he is tied to living in permanent functional dependence on other people; he is a link in the chains binding other people, just as all 
others, directly or indirectly, are links in the chains which bind him. These chains are not visible and tangible in the same way as iron chains. They are more elastic, more variable, more changeable; but they are no less real, and certainly no less strong. And it is this network of the functions which people have for each other, it and nothing else, that we call "society". It represents a special kind of sphere. Its structures are what we call "social structures". And if we talk of "social laws"or "social regularities", we are referring to nothing other than this: the autonomous laws of the relations between individual people."(Elias, 2001: 16)

And finally:

"The image of men that we need for the purpose of sociological studies cannot be the one from the singular person, the Homo sociologicus. It must be the image of persons in the plural; obviously, one must begin with a picture of a multitude of persons, each one of them, being an open and interdependent process." (Elias, 1980: 132).

In accordance with this perspective, communication scholars have as their object the encounter, the environment, the mutual recognition and the common focus on the communicative action as an independent variable. The human relation is, in fact, the indispensable condition to the fundamental historicity of the human being (cf. Elias, 2001: 55). Even ontological individualism, for which the world studied by the social sciences is made up of individuals interacting with one another, is not adapted enough to get the deep sense of networked individuals. Social action, according to Weber, is meaningful action directed towards the other. Methodologically this means an approach to verstehen (empathy) as the key word to understanding the meaningful dimension of human action and sociability.

However, individuals interacting are still individuals with respective ties and connections, suggesting a kind of sociability that finds its starting point in individuals.

This kind of ontological individualism, followed by Max Weber (1989) and phenomenologically refined by Alfred Schutz $(1967,1975,1976)$, is better adjusted to understand the communicative dimension of the social world and opens a theoretical path that is more driven by symbolic systems, enabling a focus on meaningful action.

Going a step further, Elias' thought (one could add the theoretical influence of the hermeneutical thought, symbolic interactionism and theoretical attempts by Apel, 2000, and Habermas, 1987, 1989, 1995) does not accept the idea of individuals and society as different entities: in spite of the importance of understanding the subjective point of view so extensively highlighted by both Weber and Schutz, one must bear in mind that subjectivity does not work as an essence or a black box but as something that can only be understood in the interaction with the Other.

Developing the question of interpretation, symbolic interactionism means that people act on the basis of the meaning that objects have for them, which is developed through social interaction and modified through interpretative processes employed in further interaction (Blumer, 1969). Finally, hermeneutics (for instance, Gadamer, 1992) highlights and emphasises the historicity of Being. History (culture and tradition) takes precedence over the individual. The hermeneutical process assumes a merging of horizons. In a surprising move, Habermas finds in language not 
a moment of potential domination but a place of critical activity and claims for legitimacy. Linguistics is the key to overcoming the philosophy of conscience still shared by Weber and Schutz. Giddens (1996) maintains that it is easier to support the importance of reflexivity starting from perspectives such as those supported by Mead (1969), Wittgenstein, Heidegger (1995) and Gadamer (1992). One interesting approach comes, finally, from critical realism (Bhaskar 2008, 2008-b), which describes knowledge as a process that demands the intervention of means of representation. Knowledge works as an achievement. Despite their independence from reality, current beliefs are always open to correction in light of cognitive work, including observation, experimental evidence, interpretation and theoretical reasoning. Metaphor and analogy are part of the cognitive process.

Going a second step further (bearing in mind, for instance, the work of Bruno Latour, 2012), all the meaningful encounters among human beings or between human beings and nature take place in an environment made possible by a technical device or medium. Differently from all the beings and animals that find their territory as their environment, human beings when newly born are unable to interact with other humans in a concrete territory. The only way that humans have to survive on this planet depends on the chance to invent artificial devices to build a human environment, their own world of technical objects.

Even when face-to-face, humans must use the technical device of language, the first and only medium that allows humans to mutually interact. The symbolic process is the one that explains the hominisation process. Hominisation means the attribution of meaning to objective and subjective worlds. That attribution of meaning is the phenomenon labelled as "culture" and involves not only living human beings but the existence of interactions with devices and tools. Even in the actor-network theory, this does not mean in any way a call for a post-human identity. Drawing on authors such as Gehlen (the emphasis on the technical nature of mankind), Marx (focused on labour as the key fact for understanding the human), Benjamin (studying the cultural impact of technical reproducibility) and McLuhan (the media as extension of the human being), technical agency is part of the very essence of the human.

Because of that, mediated interaction is the object of communication studies. Media are essential to producing our common human world. Mediated interaction is an essential need for human life to build a human environment. It is at once an anthropological fact that explains the nature and specific differences of human societies.

It is likely because of this particularly concern that communication sciences are partially responsible for social sciences' renewed interest in language and culture and vice-versa. Communication sciences are intrinsically responsible for building a bridge between social sciences and the theoretical questions often addressed by humanities, having brought to light the importance of culture and meaning and, consequently, the importance of hermeneutics and interpretative methods. The following issues are found to be central to any productive theory of communication: a) the importance of symbols in the meaningful constitution of the social world, b) the importance of communicative phenomena as a key element to understanding the meaning of social interaction, social networks, human agency and social structures.

Following works from interactionism, critical theory, critical realism and hermeneutics, one finds that human beings performed the communicational activity when they found themselves 
in the same environment, recognising each other as interaction partners, driving their attention towards the same reality.

Also, the cultural approach, as it emerges from sociology of culture, philosophical anthropology and cultural studies, is an important contribution that allows us to understand some key elements essential to a communication theory. The contribution by Jeffrey Alexander (1998) and other important Durkheim followers who emphasise the importance of his book Elementary Forms of Religious Life, and by anthropologists, such as Clifford Geertz (2008), interested in the symbolical dimension of social and cultural life, have brought fundamental insights to the understanding of rituals and symbolism as social phenomena.

The concern with those issues has produced huge controversies. It is unlikely that a scientific statement can maintain that the concern with symbols automatically, logically moves towards a critical approach. During its long and controversial history, the field has split itself into different paradigms that coincide with the distinction made by Habermas between instrumental and critical knowledge.

In spite of those differences, communication is, probably, the field of studies where the life of symbols has been most explicitly addressed as a study object. It is likely because of this visibility that theoretical approaches and disciplines such as critical theory, hermeneutics, cultural studies, phenomenology, and interactionism were so appealing to communication sciences and scientists. Even at times of great influence by the media industry, when economic factors seem to determine scientific research, those approaches remain strongly present, disturbing the quietness of a onesided field of study. The specific nature of communicative phenomena resists one-dimensional glances, and even in functionalist contexts one finds a practical and theoretical difficulty in forgetting and dismissing the irreducible difference of human meaning as crucial to understanding social phenomena.

Communication studies demand a reflexive and hermeneutical gaze that enables the communicative process to be understood as much more complex than a data transmission process. Without that, communication will merely address the acquisition and training of skills for transmitting information data, following a sender-receiver paradigm that is too narrow to offer a comprehensive overview of the communicative process. Likely because of this, the communication studies field seems to be a good one for observing the tension between social sciences and humanities. Whichever theoretical paradigm is embraced, the closer communication research is to a dialogue with humanities, the more likely it will be to focus its inquiry on interactions among social agents, attributing meanings to social action.

A social scientific inquiry that is more permeable to the phenomena of meaning will turn its attention to questions generally addressed by humanities in the sense of Geistewissenchaft, emphasising verstehen at the expense of ecklaren and focusing its observation on study objects such as encounters, language and culture, bringing interpretative, critical and hermeneutic methods to the research of the processes of building a meaningful collective life. Meanwhile, a typical positivist social scientific inquiry tends to see communication as a social effect, reserving theoretical attention for explaining the type of causality between communication and society. In this kind of approach, the symbol seems to lose its nature of independent variable, becoming instead a variable that changes in a deterministic sense in correlation with social structures. 
Significantly, the turn to cultural, symbolic and linguistic theorising that arose within the social sciences has had only a limited impact on sociology, probably through the remaining impact of American administrative research. In this sense, the bridge between cultural sciences and humanities was built particularly in communication and cultural studies.

\section{II}

One key premise of a post-conventional communication theory is the a priori of communication in a broader sense. Communication exists, making the human life-world and human agency possible. It really is a condition without which there would be no human agency, as it is a constituent part of the hominisation process.

Communication is fundamental to the existence of the social life-world. Without communication, there is no such thing as human sociability. Semantisation, that is to say the acquisition and sharing of meanings, is fundamental to the humanisation process, i.e. the process that leads to the emergence of human action, human agency, and human sociability. Communication has as its fundamental feature the activity of mediated interaction with the Other and the world through the use of media. Humans have forever struggled towards externalisation, building their world and not merely being launched into the surrounding environment.

Communication also involves a particular concept of the social agent, which we may conceive as a networked agent. It does not make any sense to speak of men considered individually. It makes much more sense to think of each social agent in terms of a multitude or, even better, as a network.

Communication involves a constant openness of social agents in direct agency with the social and physical worlds. Because of that, labour and language are the main processes by which men become men and the world becomes meaningful. The intersubjective process involves the existence of a medium. Mediation is the central process by which man reaches the Other and the natural world. Verstehen is understood as more than an empathic connection with the Other; it is understood as the ontological condition of human life in society as such. Language is more than a channel of practical everyday activity. Language above all expresses the human way of being in the world (Giddens, 1991: 74).

The organisation of social narrative is crucial for social life. The production of meaning is identified with the production of society. If communication exists there are unavoidable presuppositions that guide linguistic exchanges between speakers and listeners in everyday processes of communication in any language. Drawing on some Chomskian insights, one can believe that there are universal competencies that are involved when social actors interact with the aim of achieving mutual understanding (Cooke, 1998: 2). Those universal competencies are not the outcome of a particular social context or any kind of political stage from a historical point of view. They are part of a communicative process through which culture becomes a second skin for mankind.

Everyday language has an inbuilt connection with validity. Following Winch, to have a "meaning" means exactly the same as to be ruled by norms (cf. Winch, 1970; cf, Giddens, 1991: 60). No matter how profound the implications, the recognition that meaningful behaviour is necessarily oriented by norms needs some clarification (Giddens, 1991:61). There is an intrinsic 
connection between language and the normative world. However, one must include reflexivity in the norms that rule social actors. So, following Habermas, "having meaning" is not only a matter of being ruled. Linguistic interaction is also a matter of raising and responding to validity claims. Linguistic utterances as they are used in the everyday process of communication may be construed as claims to validity: to the truth, to normative rightness, to the truthfulness of the speaker (Habermas, 1998).

A theory that seeks to understand communicative action implies that the relationship of mutual recognition has an inherent rational and argumentative dimension, implying the existence of a hermeneutic process. The argumentation process is inherent to human speech. That means avoiding a final answer and the subsequent existence of an on-going and never-ending process of open interaction and argumentative dialogue. Bearing in mind the absence of a final and definitive world, the issue of legitimacy remains crucial to the very functioning of the world. This explains the established connection between the communicative process and the democratic and deliberative process in the public sphere.

References to the democratic and argumentation process that has followed reflection on logos since Ancient Greece pursue an understanding of the nature of political life. Surely, one must not follow a one-dimensional path that reduces communication to elements of collaboration, of dialogue, of ritualised sharing or interaction, avoiding conflict and domination. However, it must be maintained that language induces a claim for mutual agreement.

These considerations highlight some reasons that explain some intrinsic difficulties that sociology, or at least hegemonic sociology, has in understanding the communicative nature of society. It is likely an intrinsic difficulty that has to do with social constraints characteristic of their fields of research which demand that sociologists explain facts in a way that has focused on the institutional level, dismissing the everyday life-world. Social sciences, most of the time, are oriented towards symbolism when and only when symbols seem to be subordinated to the regularity of institutions. At its best, sociology has proficient epistemological demands when it agrees to discuss the nature of the social itself. One example is that of Niklas Luhmann (1992), a sociologist who was able to look to the symbols as a reality per se connected in systems of communication. However, his extreme idealism involved an immanent tendency towards denying the human dimension, and the status of protagonist in the process of forming meaning was given to self-referential systems. There is also the example of Habermas, when he tried to extract competencies from universal linguistics to form the grounds of a new theory of action that includes two possible ways of viewing reality, giving predominance to lived everyday interaction or institutional regularities.

When the social sciences question action, human subjectivity and the meaningful make-up of society they get closer to an intense and productive dialogue with humanities, particularly with the fields of social philosophy and epistemology. Not necessarily by chance, Habermas and Luhmann question sociology using investigation of communicative processes as a starting point. This the only way of continuing with the epistemological research that goes to the theoretical heart of human and social sciences. So the communication field will go on dealing with humanities and with the part of social sciences that questions the limits and nature of the human.

Finally, it seems that research on the new paths of capitalism labelled as the information society more than ever needs a theoretical effort that considers the empirical forces that seem to constrain 
research. In the midst of new energising forces that boost the information society, scholars can no longer be either intellectuals closed in an ivory tower or competent reproducers of empirical studies that add empirical proofs for hypotheses that are often relatively obvious.

\section{References}

Alexander, J. (1988). Durkheimian sociology: cultural studies. Cambridge University Press.

Apel, K.-O. (2000). Transformação da filosofia: filosofia analítica, semiótica, hermenêutica. São Paulo: edições Loyola.

Bhaskar, R. (2008). Dialectic: the pulse of freedom. London and New York: Routledge.

Bhaskar, R. (2008). A realist theory of science. London and New York: Routledge.

Benjamin, W. (1997-d). A obra de arte na era da sua reprodutibilidade técnica. Obras escolhidas: magia e técnica, arte e política. São Paulo: Brasiliense.

Benton, T. \& Craig, I. (2001). Philosophy of social sciences: the philosophical foundations of social thought. London: Palgrave.

Blumer, H. (1969). Symbolic interactionism: perspectives and methods. Englewood Cliffs, NJ: Prentice-Hall.

Calhoun, C. (2011). Communication as social science (and more). International Journal of Communication, 5: 1479-1496. Feature.

Carey, J. W. (1989). Communication as culture: essays on media and society. New York and London: Routledge.

Clarke, S. (2005). The neoliberal theory of society. In A. Sada-Filho \& D. Johnson (eds.), Neoliberalism: a critical reader (pp. 50-59). London, Pluto Press.

Cook, M. (1998). Preface. In J. Habermas, Pragmatics of human communication (pp. 1-20). MIT Press.

Elias, N. (1980). Introdução à sociologia. Lisbon: Edições 70.

Elias, N. (2001). The society of individuals. New York and London: Continuum.

Geertz, C. (2008). A interpretação das culturas. Rio de Janeiro: LTC.

Gehlen, A. (s.d.). A alma na era da técnica. Lisbon: Livros do Brasil (Die Seele im Technischen Zeitalter).

Giddens, A. (1996). As novas regras do método sociológio. Lisbon: Gradiva.

Foucault, M. (2008). O nascimento da biopolítica, Curso dado no Collége de France. São Paulo: Martins Fontes.

Gadamer, H.-G. (1992). A universalidade do problema hermenêutico. In J. Bleischer, Hermenêutica contemporânea. Lisbon: Edições 70.

Habermas, J. (1987). Théorie de l'agir comunicationnel, 2 vols. Paris: Fayard. (Theorie des kommunikativen handelns, 1982-3). 
Habermas, J. (1998). On the pragmatics of communication. MIT Press.

Habermas, J. (1995). Communication and the evolution of society. London: Polity Press.

Heidegger, M. (1995). O ser e o tempo. Petropólios: Vozes. (Sein und Zeit, 1927).

Latour, B. (2012). Reagregando o social: uma introdução à teoria do ator-rede. São Paulo: EDUSC.

Luhmann, N. (1992). A improbabilidade da comunicação. Lisbon: Vega.

Marx, K. (1971). Manuscritos económico-filosóficos. Porto: Brasília Editora.

McLuhan, M. (2005). Os meios de comunicação como extensão do homem. São Paulo: Cultrix.

Mead, G.-H. (1969). Mind, self and society. Chicago: Chicago University Press.

Parry-Gilles, T. (2013). Humanities or social science?. Communication Matters. NCA's ACADEmic, Teaching, And Research Blog. Accessed on 31-10-2016 at the following URL: https://ncablog.org/

Schutz, A. (1975). Collected papers, the problem of social reality, vol. I. The Hague: Martinus Nijoff.

Schutz, A. (1976). Collected papers, studies in social theory, vol. II. The Hague: Martinus Nijoff.

Schutz, A. (1967). The phenomenology of the social world. Evanston, Illinois: Northwestern University Press.

Weber, M. (1989). Economía y sociedad. México: Fondo de Cultura Económica.

Winch, P. (1970). A ideia de uma ciência social e sua relação com a filosofia. São Paulo: Editora Nacional. 